Supporting Information for

\title{
Anomalous Size-Dependent Excited-Stated Relaxation Dynamics of NanoGUMBOS
}

\author{
Tony E. Karam, Noureen Siraj, Isiah M. Warner, Louis H. Haber* \\ Department of Chemistry, Louisiana State University, Baton Rouge, Louisiana 70803, United States. \\ *e-mail: lhaber@1su.edu
}

\section{Characterization of GUMBOS and NanoGUMBOS}

The $\left[\mathrm{Ru}(\text { bipy })_{3}\right][\mathrm{BETI}]_{2}$ GUMBOS are characterized using nuclear magnetic resonance (both ${ }^{1} \mathrm{H}-\mathrm{NMR}$ and ${ }^{19} \mathrm{~F}-\mathrm{NMR}$ ), mass spectrometry, X-ray diffraction (XRD), X-ray crystallography, thermogravimetric analysis (TGA), and differential scanning calorimetry (DSC). The $\left[\mathrm{Ru}(\text { bipy })_{3}\right][\mathrm{BETI}]_{2}$ nanoGUMBOS are additionally characterized using transmission electron microscopy (TEM), ultraviolet-visible absorption spectroscopy, and fluorescence spectroscopy. The chemical structures of ruthenium(II)-tris-(2,2'-bipyridine) and bis(pentafluoroethylsulfonyl)imide that make up the $\left[\mathrm{Ru}(\text { bipy })_{3}\right][\mathrm{BETI}]_{2}$ nanoGUMBOS are shown in Figure $\mathrm{S} 1$. The ${ }^{1} \mathrm{H}-\mathrm{NMR}$ spectra of the $\left[\mathrm{Ru}(\text { bipy })_{3}\right][\mathrm{BETI}]_{2}$ GUMBOS in dimethyl sulfoxide are performed using a Bruker Avance $400 \mathrm{MHz}$ NMR spectrometer and show peaks at $\delta 8.83(\mathrm{~d}, \mathrm{~J}=7.96 \mathrm{~Hz}, 6 \mathrm{H}), 8.17(\mathrm{t}, \mathrm{J}=7.32,6 \mathrm{H}), 7.72(\mathrm{~d}, \mathrm{~J}=5.68 \mathrm{~Hz}, 6 \mathrm{H})$, and $7.53(\mathrm{t}, \mathrm{J}=6.18,6 \mathrm{H})$.

Similarly, the ${ }^{19} \mathrm{~F}-\mathrm{NMR}$ spectra show peaks at $\delta-117.64$ and -79.33 . Mass spectrometry is performed using a Bruker Ultraflextreme MALDI TOF mass spectrometer to measure the mass to charge ratios of $570 \mathrm{amu}$ for the cation and $380 \mathrm{amu}$ for the anion, as expected for these molecular ions. The X-ray diffraction pattern of the GUMBOS, shown in Figure S2, displays many sharp 
lines illustrating the high crystallinity of the sample. Additionally, X-ray crystallography is performed to determine that the crystal structure has monoclinic symmetry with a $\mathrm{C} 2 / \mathrm{c}$ space group. The $a, b$, and $c$ cell lengths are determined to be $24.4334 \AA$, $15.4669 \AA$, and $17.4480 \AA$, respectively, with a total cell volume of $4734.7 \AA^{3}$. The alpha, beta, and gamma cell angles are 90 degrees, 134.105 degrees, and 90 degrees, respectively.

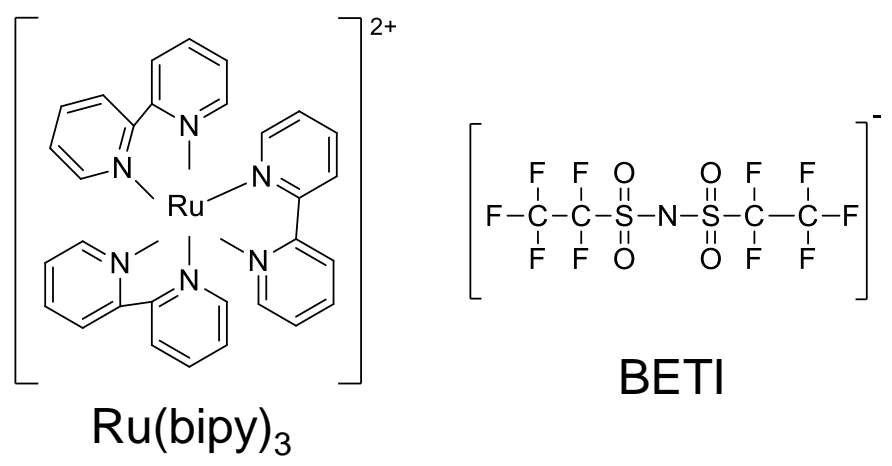

Figure S1. Chemical structures of the $\mathrm{Ru}(\text { bipy })_{3}{ }^{2+}$ and $\mathrm{BETI}^{-}$molecular ions.

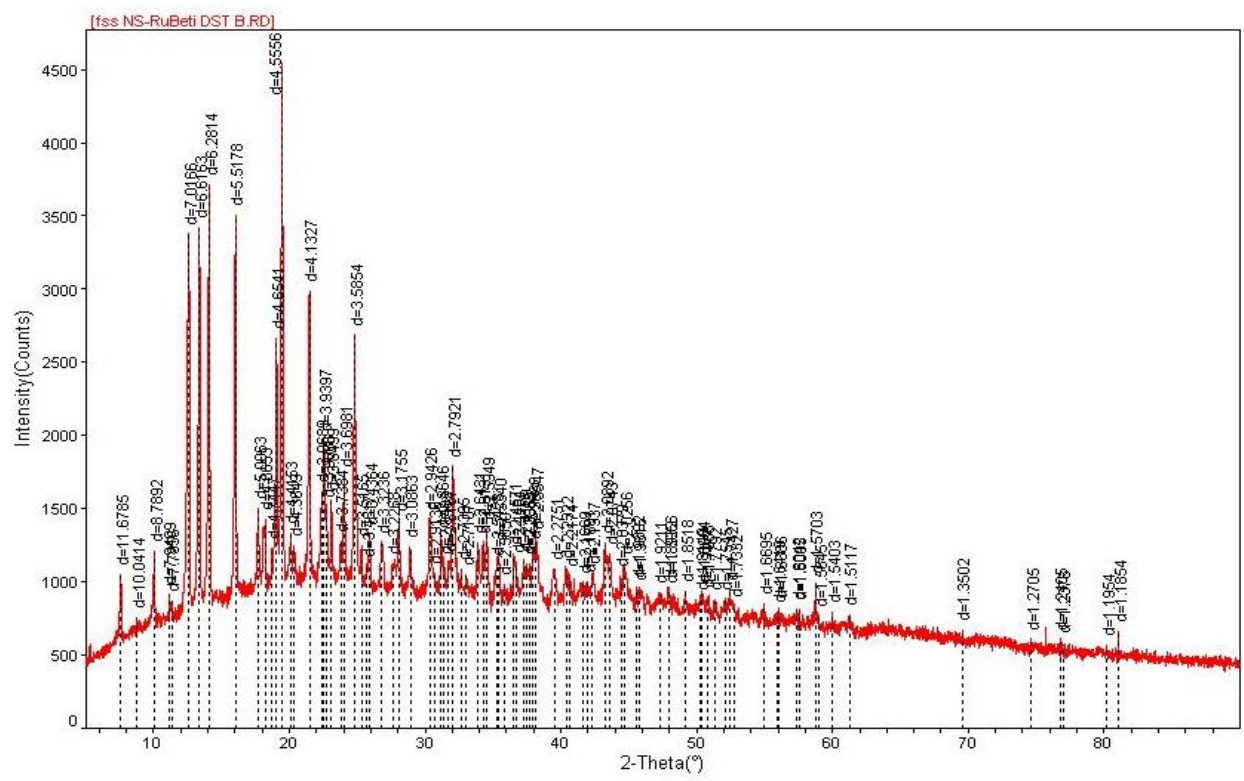

Figure. S2. Powder X-ray diffraction pattern of $\left[\mathrm{Ru}(\text { bipy })_{3}\right][\mathrm{BETI}]_{2}$ GUMBOS. 
Thermogravimetric analysis using a Hi Res Modulated TGA 2950 shows that the $\left[\mathrm{Ru}(\text { bipy })_{3}\right][\mathrm{BETI}]_{2}$ GUMBOS have high purity and thermal stability. The sample is heated from room temperature to $600{ }^{\circ} \mathrm{C}$ at the rate of $10^{\circ} \mathrm{C} \mathrm{min}-1$, with the TGA plot shown in Figure S3 revealing a very high decomposition temperature of around $385{ }^{\circ} \mathrm{C}$, compared to several decomposition temperatures near $100{ }^{\circ} \mathrm{C}, 140{ }^{\circ} \mathrm{C}, 330{ }^{\circ} \mathrm{C}$, and $380{ }^{\circ} \mathrm{C}$ for $\left[\mathrm{Ru}(\text { bipy })_{3}\right] \mathrm{Cl}_{2} \cdot 6 \mathrm{H}_{2} \mathrm{O} .{ }^{1}$ [1] The thermal phase transition characteristic of the $\left[\mathrm{Ru}(\text { bipy })_{3}\right][\mathrm{BETI}]_{2}$ GUMBOS is studied with a Q100 differential scanning calorimeter (DSC, TA instruments, New Castle, DE). A few milligrams of the GUMBOS is weighed in an aluminum crucible and sealed with an aluminum lid. The sample is scanned from $-40{ }^{\circ} \mathrm{C}$ to $250{ }^{\circ} \mathrm{C}$ with a rate of $5{ }^{\circ} \mathrm{C} \mathrm{min}-1$ under a nitrogen flow of $50 \mathrm{~mL} \mathrm{~min}^{-1}$. Figure $\mathrm{S} 4$ shows that the GUMBOS display a very sharp melting point peak at 230 ${ }^{\circ} \mathrm{C}$ with no evidence of a glass transition peak, demonstrating that the compound is highly crystalline and free of impurities. This contrasts with previous differential scanning calorimetry measurements on $\left[\mathrm{Ru}(\text { bipy })_{3}\right] \mathrm{Cl}_{2} \cdot 6 \mathrm{H}_{2} \mathrm{O}$ which show several broad peaks between $100{ }^{\circ} \mathrm{C}$ and 400 ${ }^{\circ} \mathrm{C}$. The melting point of the GUMBOS measured using MPA 160 and MPA 161 DigiMelt SRS systems is consistent with the melting point determined from differential scanning calorimetry.

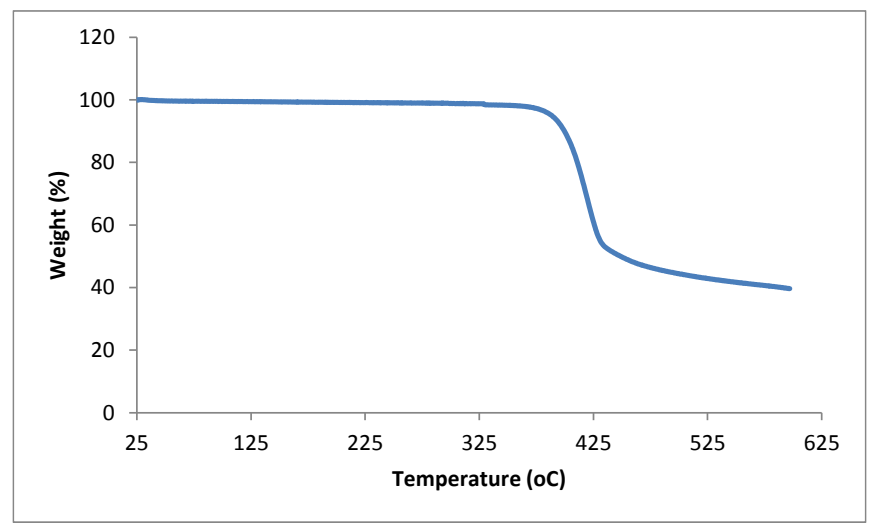

Figure S3. TGA plot for $\left[\mathrm{Ru}(\text { bipy })_{3}\right][\mathrm{BETI}]_{2}$ GUMBOS. 


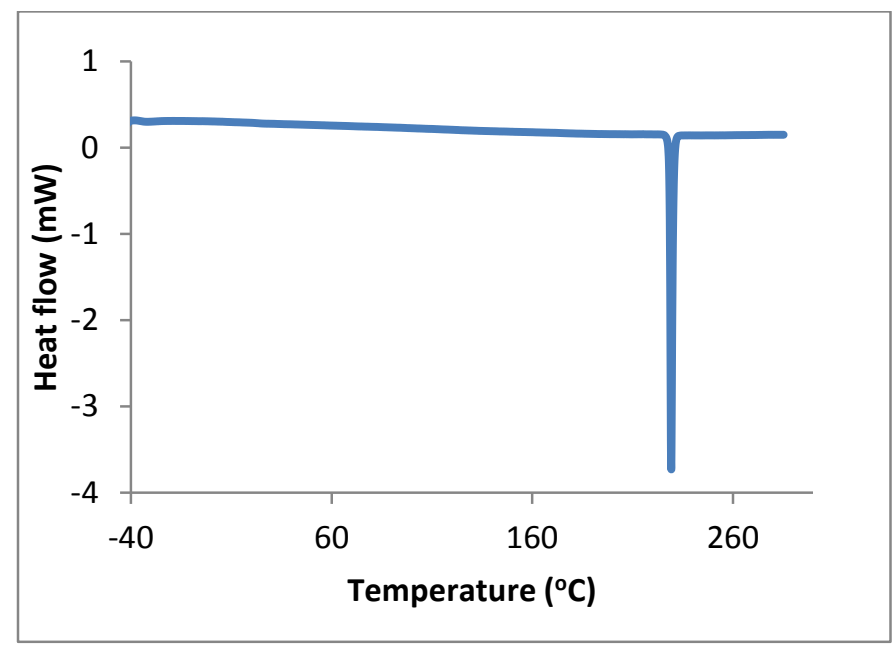

Figure S4. DSC plot for GUMBOS showing a sharp melting peak.

Transmission electron microscopy of nanoGUMBOS is obtained using a Dulong America's LVEMS Benchtop TEM to measure the size distribution and morphology of the nanoparticles. Aliquots of $4 \mu \mathrm{L}$ from the nanoGUMBOS aqueous solutions, prepared under different ultrasonication conditions as described in the paper, are placed on separate carbon-coated copper grid and air-dried at room temperature overnight. TEM images, shown in Figure S5 (a), (b), and (c), determine the nanoparticles to be spherical in shape with size distributions of $97 \mathrm{~nm}$ $\pm 19 \mathrm{~nm}$, (b) $56 \mathrm{~nm} \pm 13 \mathrm{~nm}$, and (c) $23 \mathrm{~nm} \pm 5 \mathrm{~nm}$, respectively. 

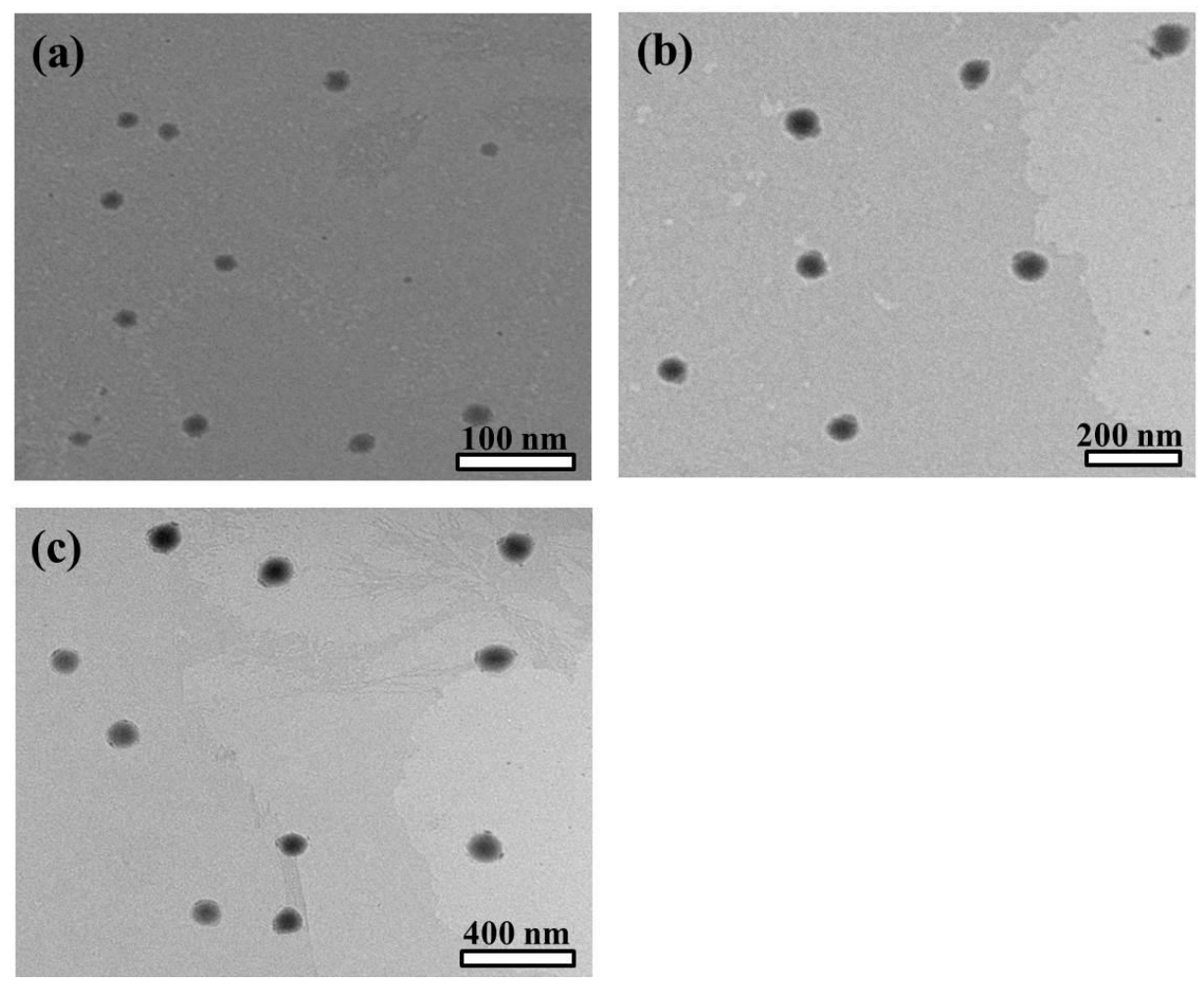

Figure S5. Transmission electron microscopy (TEM) images of the $\left[\mathrm{Ru}(\mathrm{bipy})_{3}\right][\mathrm{BETI}]_{2}$ nanoGUMBOS prepared under varying ultrasonication conditions showing size distributions of (a) $23 \mathrm{~nm} \pm 5 \mathrm{~nm}$, (b) $56 \mathrm{~nm} \pm 13 \mathrm{~nm}$, and (c) $97 \mathrm{~nm} \pm 19 \mathrm{~nm}$, respectively.

Ultraviolet-visible absorption spectra of $70 \mu \mathrm{M}$ aqueous $\mathrm{Ru}(\text { bipy })_{3} \mathrm{Cl}_{2}$ and the $\left[\mathrm{Ru}(\text { bipy })_{3}\right][\mathrm{BETI}]_{2}$ nanoGUMBOS in water are displayed in Figure S6. The $\left[\mathrm{Ru}(\text { bipy })_{3}\right][\mathrm{BETI}]_{2}$ nanoGUMBOS are prepared to have the same overall ruthenium bipyridine concentrations of 70 $\mu \mathrm{M}$ for direct comparisons with the aqueous $\mathrm{Ru}(\text { bipy })_{3} \mathrm{Cl}_{2}$ measurements. The nanoGUMBOS and dye solutions show similar peaks, with the high energy peak at $290 \mathrm{~nm}$ assigned to the ligand to ligand (LL) $\pi-\pi^{*}$ transition while the second peak near $455 \mathrm{~nm}$ is ascribed to the singlet metal to ligand charge transfer (MLCT) $\left(\mathrm{d}-\pi^{*}\right)$ transition. The molar extinction coefficients decrease significantly in nanoGUMBOS, possibly due to molecular confinement and optical shielding of internal molecules in the central volume of the nanoGUMBOS by molecules closer to the surface. 


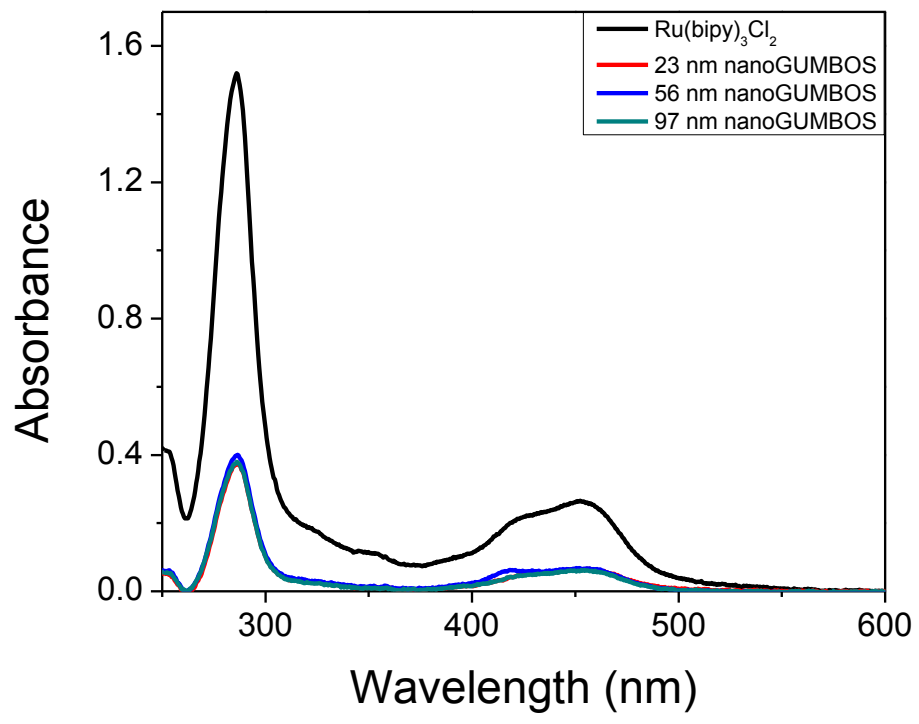

Figure S6. Absorption spectra of aqueous $\mathrm{Ru}(\text { bipy })_{3} \mathrm{Cl}_{2}$ (black line) and $\left[\mathrm{Ru}(\text { bipy })_{3}\right][\mathrm{BETI}]_{2}$ nanoGUMBOS with average sizes of $23 \mathrm{~nm}$ (red line), $56 \mathrm{~nm}$ (blue line), and $97 \mathrm{~nm}$ (green line).

Transient Absorption Time Profiles and Fits

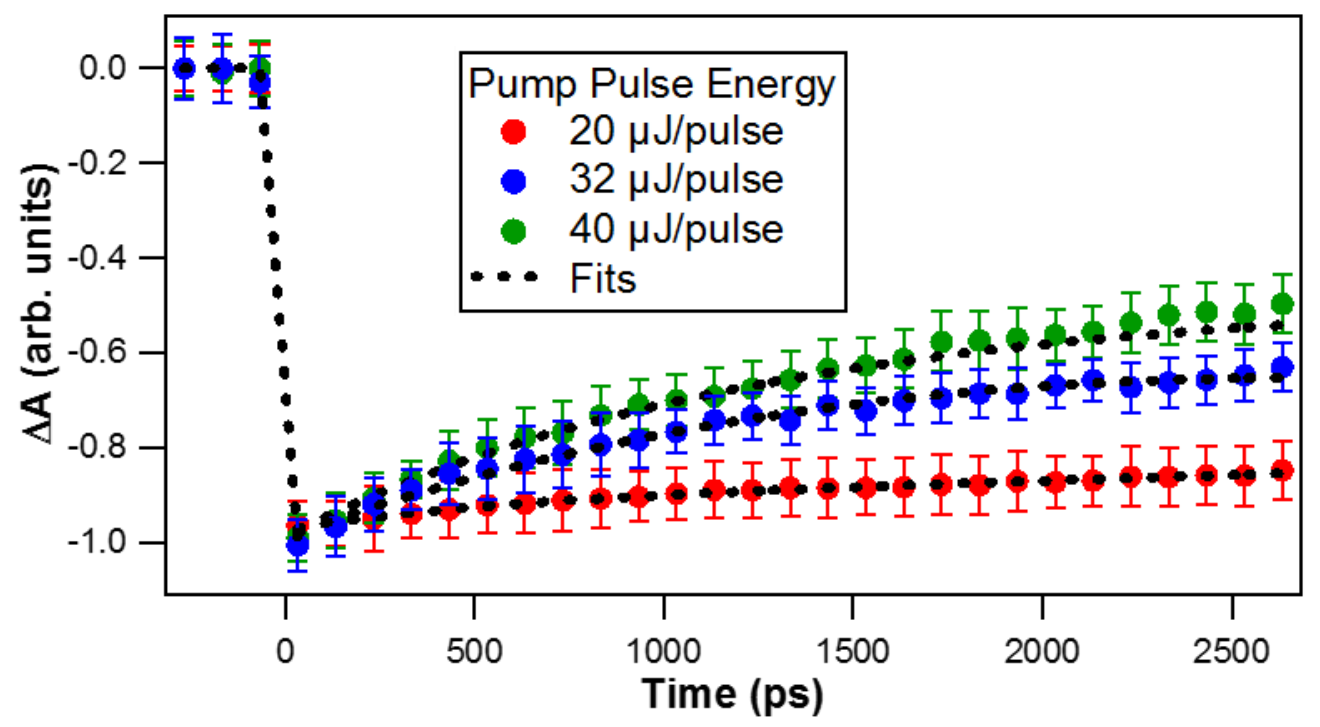

Figure S7. Time-dependent transient absorption spectra of $0.4 \mathrm{mM}$ aqueous $\mathrm{Ru}(\mathrm{bipy})_{3} \mathrm{Cl}_{2}$ measured at $450 \mathrm{~nm}$ at various pump pulse energies. The data are fit using bi-exponential functions. 
Figure S7 shows the transient absorption ground-state depletion time profiles of aqueous $\mathrm{Ru}$ (bipy) ${ }_{3} \mathrm{Cl}_{2}$ using excitation with $400 \mathrm{~nm}$ pump pulse energies of 20,32 , and $40 \mu \mathrm{J}$. The spectra are normalized for clarity. The relaxation decays are fit using bi-exponential functions of the form $y_{0}+A_{1} \exp \left(-\frac{t}{\tau_{1}}\right)+A_{2} \exp \left(-\frac{t}{\tau_{2}}\right)$ to obtain the lifetimes and amplitudes of the fits, which are given are Table $\mathrm{S} 1$. These relaxation decays are attributed to excited states of $\mathrm{Ru}(\text { bipy })_{3}{ }^{2+}$ that are accessible through multi-photon processes that are only observed at higher pump pulse energies. The values of the lifetimes and the ratio of $A_{1} / A_{2}$ at different pump pulse energies remain fairly constant to within experimental uncertainty. These lifetimes are similar to the ones obtained from transient absorption on the size-dependent $\left[\mathrm{Ru}(\text { bipy })_{3}\right][\mathrm{BETI}]_{2}$ nanoGUMBOS, signifying that these are the same states involved in the relaxation dynamics.

\begin{tabular}{cccccc}
\hline $\begin{array}{c}\text { Pump Pulse Energy } \\
(\mu \mathrm{J})\end{array}$ & $\tau_{1}(\mathrm{ps})$ & $\tau_{2}(\mathrm{ps})$ & $\mathrm{A}_{1}$ & $\mathrm{~A}_{2}$ & $y_{0}$ \\
\hline 20 & $8196 \pm 523$ & $3639 \pm 280$ & $1.1 \pm 0.2$ & $-0.8 \pm 0.1$ & $1.3 \pm 0.1$ \\
32 & $8020 \pm 408$ & $3590 \pm 182$ & $4.4 \pm 0.5$ & $-3.0 \pm 0.3$ & $1.7 \pm 0.1$ \\
40 & $7905 \pm 370$ & $3475 \pm 128$ & $3.5 \pm 0.5$ & $-2.8 \pm 0.3$ & $2.4 \pm 0.1$
\end{tabular}

Table S1. Time constants and amplitudes obtained from fitting the ground-state depletion decays using bi-exponential functions at various excitation energies.

Figures S8, S9, and S10 display representative transient absorption time profiles of the 23 $\mathrm{nm}, 56 \mathrm{~nm}$, and $97 \mathrm{~nm}\left[\mathrm{Ru}(\text { bipy })_{3}\right][\mathrm{BETI}]_{2}$ nanoGUMBOS, respectively, at probe wavelengths of $420 \mathrm{~nm}, 430 \mathrm{~nm}$, and $455 \mathrm{~nm}$, after the baseline shifts are subtracted. All transient absorption time profiles are fit to the functions $A_{1} \exp \left(-\frac{t}{T_{1}}\right)+A_{2} \exp \left(-\frac{t}{\tau_{2}}\right)+A_{3} \exp \left(-\frac{t}{\tau_{3}}\right)$ where $A_{i}$ and $\tau_{i}$ are the amplitudes and lifetimes of the $i^{\text {th }}$ dynamical process, respectively, ${ }^{3}$ for each wavelength for each nanoGUMBOS sample, as described in the manuscript. The relative contributions for 
each fit for the time profiles for the different nanoGUMBOS samples are shown in Figures S8, S9, and $\mathrm{S} 10$, along with the total fits. The lifetimes $\tau_{1}, \tau_{2}$, and $\tau_{3}$ are attributed to the non-standard triplet metal centered complex, the non-standard triplet metal to ligand charge transfer complex, and intermolecular energy transfer, respectively. The amplitudes vary with wavelength to determine the decay spectra for each lifetime, shown in Figure 6 of the manuscript. The time constants obtained from fits of transient absorption of the nanoGUMBOS are listed in Table S2. 

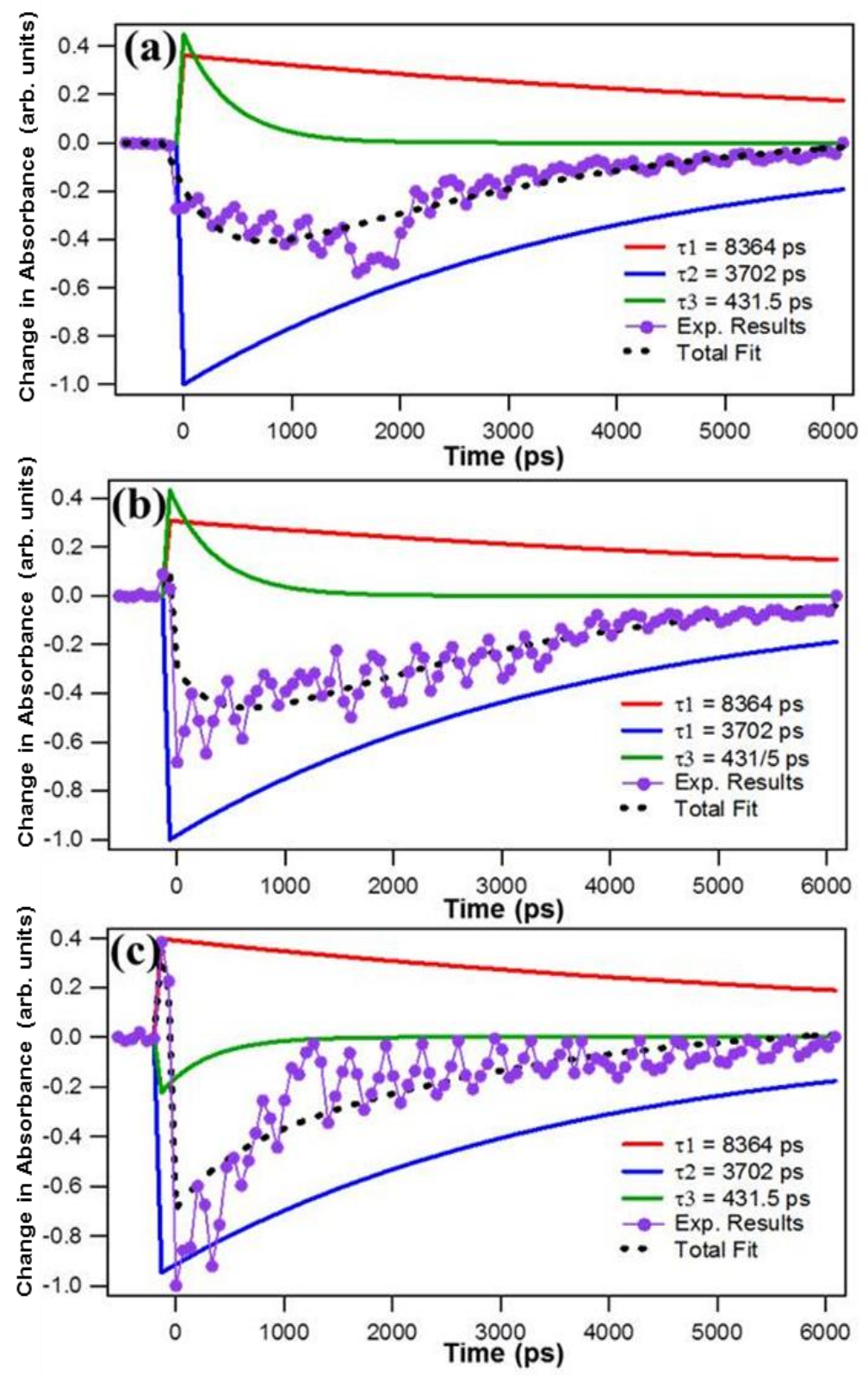

Figure S8. Representative time profiles of $23 \mathrm{~nm}\left[\mathrm{Ru}(\text { bipy })_{3}\right][\mathrm{BETI}]_{2}$ nanoGUMBOS measured at probe wavelengths of (a) $420 \mathrm{~nm}$, (b) $430 \mathrm{~nm}$, and (c) $455 \mathrm{~nm}$. The experimental data are fit using a sum of multiple exponential functions and individual plots are generated as a function of pump-probe time delay. 

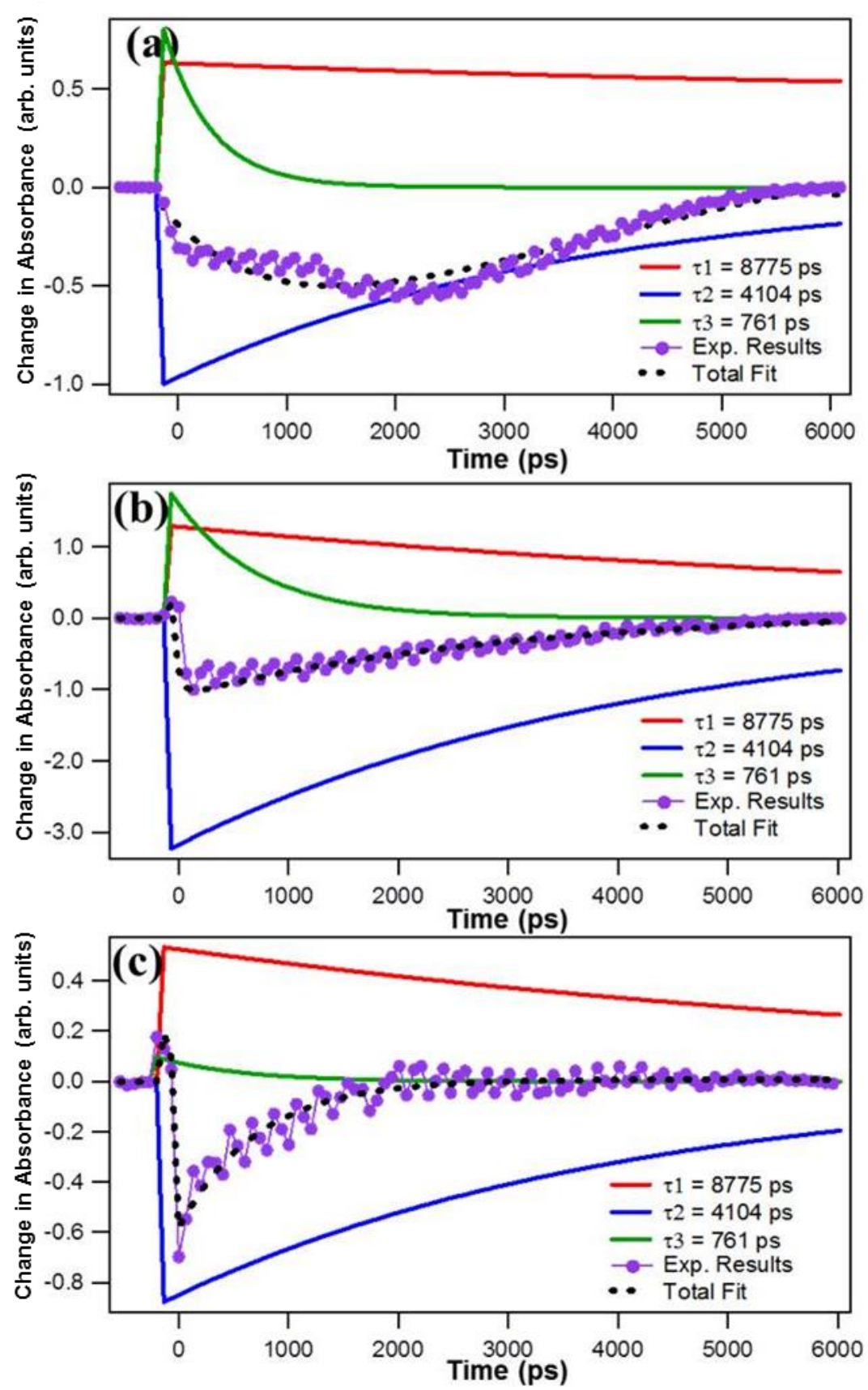

Figure S9. Representative time profiles of $56 \mathrm{~nm}\left[\mathrm{Ru}(\text { bipy })_{3}\right][\mathrm{BETI}]_{2}$ nanoGUMBOS measured at probe wavelengths of (a) $420 \mathrm{~nm}$, (b) $430 \mathrm{~nm}$, and (c) $455 \mathrm{~nm}$. The experimental data are fit using a sum of multiple exponential functions and individual plots are generated as a function of pump-probe time delay. 

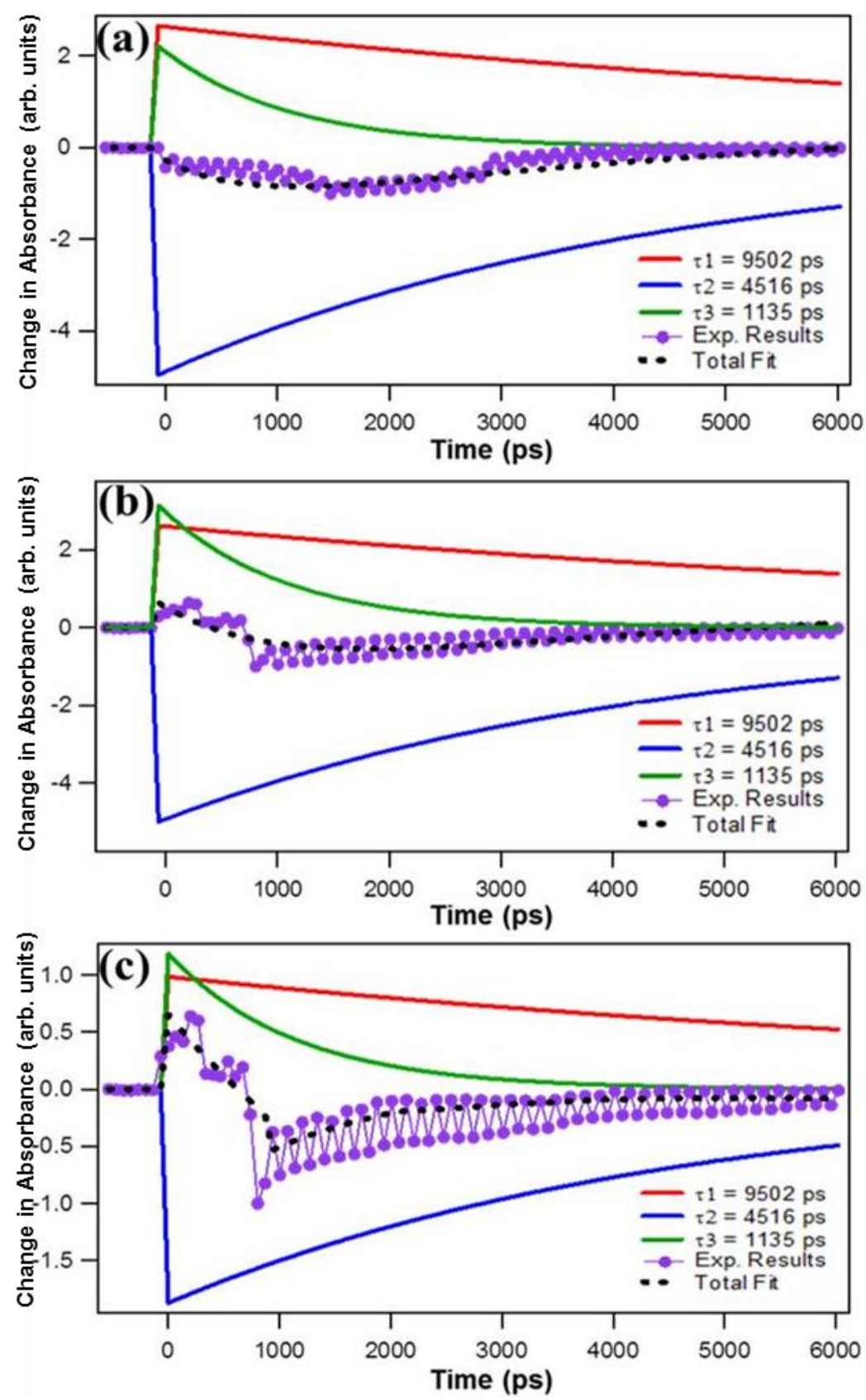

Figure S10. Representative time profiles of $97 \mathrm{~nm}\left[\mathrm{Ru}(\text { bipy })_{3}\right][\mathrm{BETI}]_{2}$ nanoGUMBOS measured at probe wavelengths of (a) $420 \mathrm{~nm}$, (b) $430 \mathrm{~nm}$, and (c) $455 \mathrm{~nm}$. The experimental data are fit using a sum of multiple exponential functions and individual plots are generated as a function of pump-probe time delay. 


\begin{tabular}{cccc}
\hline diameter $(\mathrm{nm})$ & $\tau_{1}(\mathrm{ps})$ & $\tau_{2}(\mathrm{ps})$ & $\tau_{3}(\mathrm{ps})$ \\
\hline 23 & $8364 \pm 65$ & $3702 \pm 41$ & $432 \pm 76$ \\
56 & $8775 \pm 136$ & $4104 \pm 55$ & $761 \pm 22$ \\
97 & $9502 \pm 74$ & $4516 \pm 72$ & $1135 \pm 122$
\end{tabular}

Table S2. Time constants obtained from fits of spectrally-resolved transient absorption time profiles from $\left[\mathrm{Ru}(\text { bipy })_{3}\right][\mathrm{BETI}]_{2}$ nanoGUMBOS using a sum of exponential functions.

\section{Phonon Analysis of $\left.[\text { Ru(bipy })_{3}\right][\text { BETI }]_{2}$ nanoGUMBOS}

The time-dependent differences between the experimental measurements and the multiexponential best fits for the nanoGUMBOS contain the phonon oscillations for additional analysis. Figure S11 shows the residual oscillations of the phonons that are fit using a sinusoidal function given by $I(t)=y_{0}+A \exp \left(-\frac{t}{\tau_{4}}\right) \sin (2 \pi f t+\varphi)$, where f, $\varphi$, and $\tau_{4}$ are the frequency, the phase shift, and phonon lifetime, respectively. The curves are offset for clarity. These oscillations are measured at $445 \mathrm{~nm}$ for the best signal to noise, although the same phonon lifetimes and frequencies are observed at all wavelengths, to within experimental uncertainty. Figure S12 shows the residual transient absorption signal oscillations from the three nanoGUMBOS samples between the pump-probe time delay of $900 \mathrm{ps}$ and $2000 \mathrm{ps}$ at higher temporal resolutions with the corresponding sinusoidal fits. The oscillation periods, phase shifts, and phonon lifetimes for the different nanoGUMBOS sizes are shown in Table S3. These values are consistent between the lower temporal resolution scans, shown in Figure S11, and the higher temporal resolution scans, shown in Figure S12, to within experimental uncertainty. 


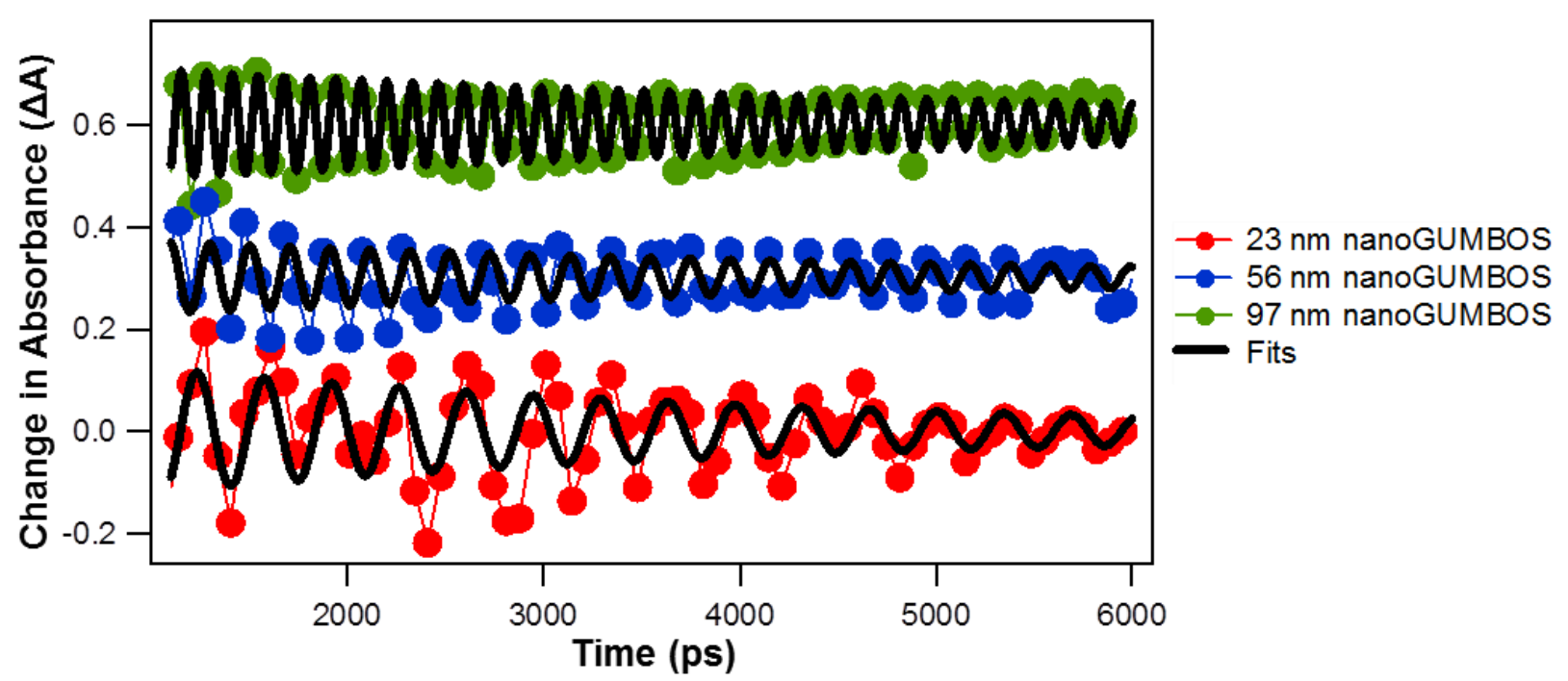

Figure S11. Residual signals from the transient absorption time profiles after subtracting the multiexponential best fits, showing the phonon oscillations for the different nanoGUMBOS sizes, along with the corresponding fits. 

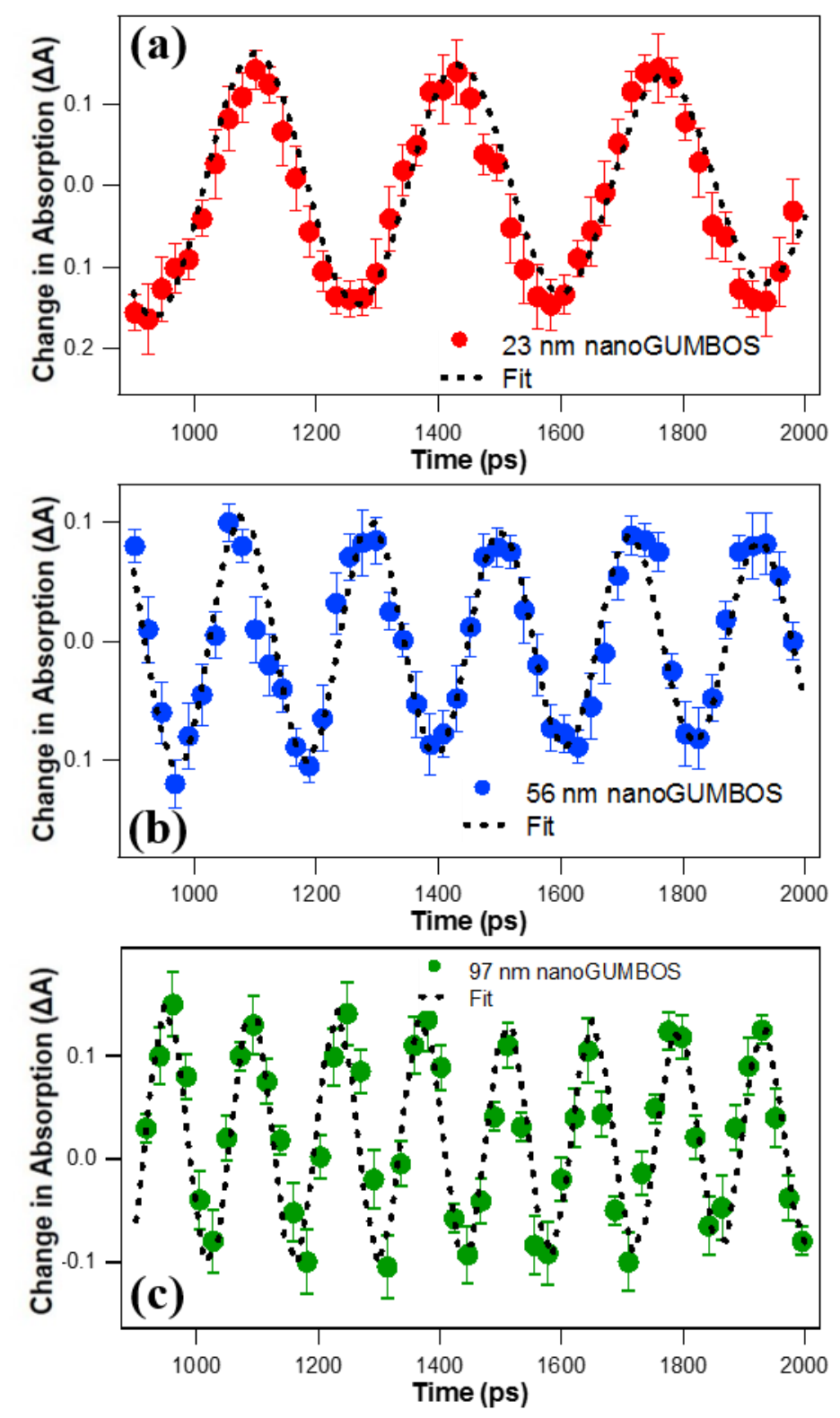

Figure S12. Residual signals from the transient absorption time profiles of the (a) $23 \mathrm{~nm}$, (b) 56 $\mathrm{nm}$, and (c) $97 \mathrm{~nm}$ nanoGUMBOS after subtracting the corresponding multiexponential best fits, showing the phonon oscillations under higher temporal resolution along with the corresponding fits. 


\begin{tabular}{cccc}
\hline diameter $(\mathrm{nm})$ & $\mathrm{T}_{\mathrm{ac}}(\mathrm{ps})$ & $\varphi(\mathrm{rad})$ & $\tau_{4}(\mathrm{ps})$ \\
\hline 23 & $334 \pm 6$ & $5.9 \pm 0.1$ & $3426 \pm 354$ \\
56 & $209 \pm 5$ & $3.5 \pm 0.2$ & $4119 \pm 521$ \\
97 & $140 \pm 4$ & $2.9 \pm 0.1$ & $5163 \pm 594$ \\
\hline
\end{tabular}

Table S3. Size-dependent acoustic phonon oscillation periods, phase shifts, and phonon lifetimes of the $\left[\mathrm{Ru}(\text { bipy })_{3}\right][\mathrm{BETI}]_{2}$ nanoGUMBOS.

The frequencies of the phonon oscillations can be fit using a model based on the sizedependent force constant of the nanocrystals. ${ }^{4}$ The size-dependent frequencies can be written as a function of the size-dependent bond energy and bond length, where structural properties and thermodynamic parameters play an important role on the size-dependent phonons. The vibration frequency of bulk crystals $\omega_{b}$ can be written as

$$
\omega_{b}=c_{2} \times\left(\frac{\varepsilon}{h^{2}}\right)^{\frac{1}{2}}
$$

where $\varepsilon$ is the bond energy, $h$ is the bond length, and $c_{2}$ is a constant. The size-dependent frequency $\omega(d)$ can be written as

$$
\omega(d)=c_{2}\left[\frac{\varepsilon(d)}{h(d)^{2}}\right]^{\frac{1}{2}}
$$

where $d$ the diameter of the nanoparticles, $\varepsilon(d)$ is the size-dependent bond energy, and $h(d)$ is the size-dependent bond length. The ratio of the size-dependent frequency to the vibration frequency of bulk crystals is given by

$$
\frac{\omega(d)}{\omega_{b}}=\frac{h}{h(d)} \sqrt{\frac{\varepsilon(d)}{\varepsilon}}
$$


with $\frac{h}{h(d)}=\frac{1}{1 \pm \frac{3}{2 d} \sqrt{\frac{\kappa d_{0} h S_{v i b} H_{m} T^{2}}{R V_{c} T_{m}^{2}}}}$

where $\kappa$ is the compressibility of the crystal, $d_{0}$ is the critical size, $S_{v i b}$ is the vibrational entropy, $H_{m}$ is the enthalpy at the melting point $T_{m}, V_{c}$ is molar volume of the crystal, and $R$ is the ideal gas constant. The \pm sign is carried during the derivation from the expression of the surface stress of the nanocrystals with $\frac{8 \kappa f^{2}}{3 \gamma_{0}}=d_{0}$, where $\gamma_{0}$ is the bulk value of the excess free energy. ${ }^{5} \gamma_{0}$ is approximated using the Gibbs-Thomson equation. ${ }^{6}$ Both positive and negative values of the stress are possible depending on the interface structure of the nanocrystals, which can result in either lattice expansion or lattice contraction, respectively. The ratio of $\varepsilon(d)$ to $\varepsilon$ can be written as

$$
\frac{\varepsilon(d)}{\varepsilon}=\frac{1-\frac{6 \gamma_{s} V_{c}}{E d}}{1-\frac{n_{s}}{n} \frac{d_{0}}{d}}
$$

where $\gamma_{s}$ is the excess surface free energy of the crystal, $E$ is the cohesion energy of one molar crystal, $n$ is the coordination number of an atom or molecule in the bulk crystal, and $n_{s}$ is the decrease of surface coordination number compared to $n$.

Figure S13 shows the fitting of the experimental results of $\omega(d) / \omega_{b}$ as a function of the nanoparticle diameter $d$ using this model, showing good agreement. The value of $h$ estimated from the crystal structure is $0.52 \mathrm{~nm}$. The melting point $\mathrm{T}_{\mathrm{m}}$ of the nanoGUMBOS used in the fit is 503 K. $V_{c}$ is determined from the ratio of the molar mass of $\left[\mathrm{Ru}(\text { bipy })_{3}\right][\mathrm{BETI}]_{2}$ to the density of the unit cell to be $2845 \mathrm{~cm}^{3} \cdot \mathrm{mol}^{-1} \cdot n_{s} / n$ is determined for a monoclinic crystal structure to be 0.5 . The other values used in the phonon fit are estimated to be approximately equal to the values provided in reference 3 while providing the best fit for the experimental data with $\kappa=0.5 \times 10^{-10} \mathrm{~Pa}^{-1}$, 
$\mathrm{d}_{0}=3.12 \mathrm{~nm}, \mathrm{~S}_{\mathrm{vib}}=10 \mathrm{~J} \cdot \mathrm{g}-$ atom $^{-1} \mathrm{~K}^{-1}, \mathrm{H}_{\mathrm{m}}=100 \times 10^{3} \mathrm{~J}_{\mathrm{mol}} \mathrm{mol}^{-1}, \gamma_{\mathrm{s}}=0.5 \mathrm{~J} \cdot \mathrm{m}^{-2},, \mathrm{E}=$ $400 \times 10^{3} \mathrm{~J}_{\mathrm{mol}} \mathrm{mol}^{-1}$, and $\omega_{\mathrm{b}}=0.0074 \mathrm{ps}^{-1}$.

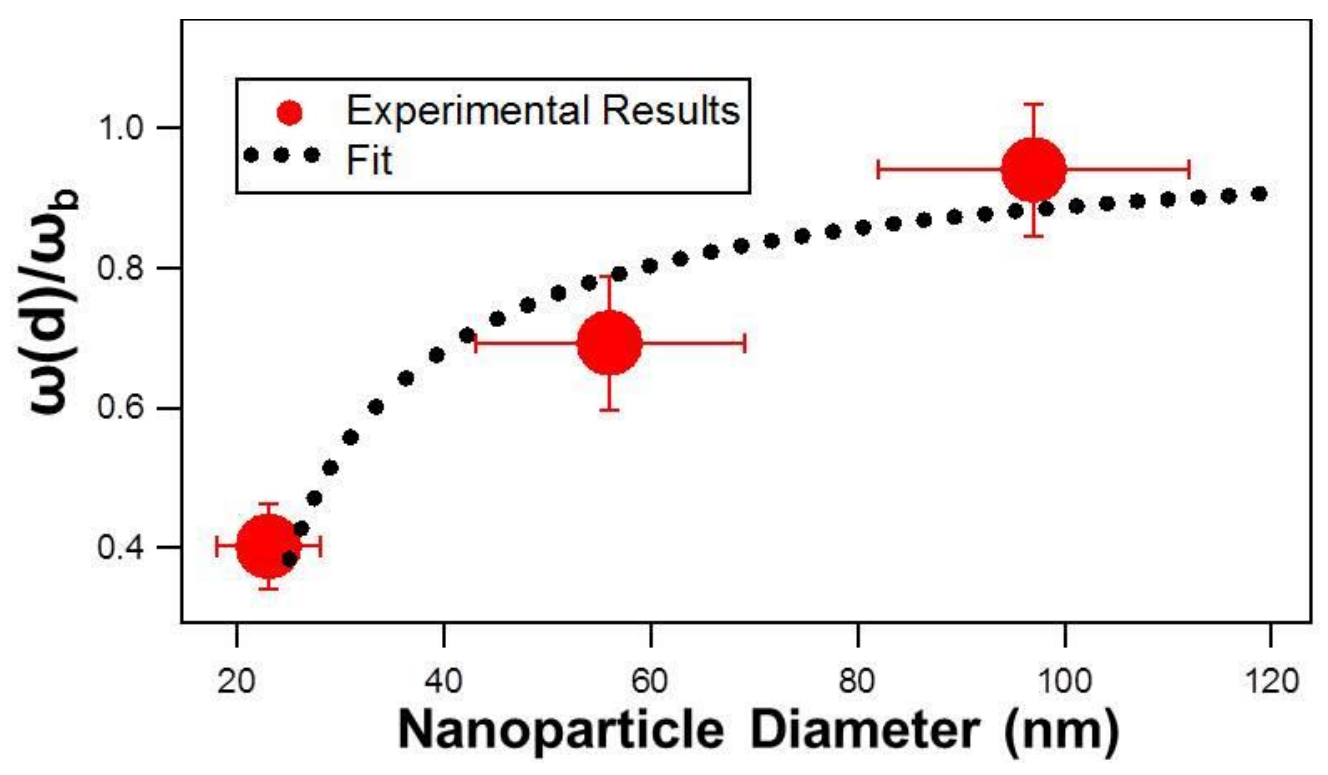

Figure S13. Ratio of the size-dependent frequency to the bulk frequency of $\left[\mathrm{Ru}(\text { bipy })_{3}\right][\mathrm{BETI}]_{2}$ nanoGUMBOS as a function of nanoparticle size. The experimental data are fit using a model based on the size-dependent force constant of the nanocrystals.

The crystalline nanoGUMBOS are held together by relatively weak electrostatic and van der Waals forces, so it is very likely that the effects of the bulk and shear viscosity on the surface are more significant compared to closely-packed metallic or semiconductor nanoparticles, such as gold, silver, and titanium dioxide, which have much stronger bonding throughout the crystalline material. Additionally, the strong interaction of the nonpolar molecules at the nanoGUMBOS surface with the polar water solvent is expected to lead to lattice contraction, which is described using the negative sign in the equation for the size-dependence bond lengths. This model is shown to be an accurate description of the observed size-dependent phonon frequencies of these crystalline nanoGUMBOS, suggesting that significant surface stress due to the interaction with the 
aqueous solvent results in a size-dependent lattice contraction and the anomalous trend where phonon frequencies increase with increasing nanoparticle size. We have also analyzed these nanoGUMBOS in $\mathrm{D}_{2} \mathrm{O}$ and have preliminary data which are consistent with our hypothesis of this phenomenon. Further studies are underway in $\mathrm{D}_{2} \mathrm{O}$ and changing $\mathrm{pH}$ conditions and these observations will be reported in a subsequent manuscript.

\section{REFERENCES}

1. Amman, A.; Easton, E. B. Novel Organic-Inorganic Hybrid Material Based on Tris(2,2’bipyridyl)dichlororuthenium(II) Hexahydrate and Dawson-Type Tungstophosphate $\mathrm{K}_{7}\left[\mathrm{H}_{4} \mathrm{PW}_{18} \mathrm{O}_{62}\right] \cdot 18 \mathrm{H}_{2} \mathrm{O}$ as a Bifuctional Hydrogen Peroxide Electrocatalyst for Biosensors. Sensors and Actuators B 2012, 161, 520-527.

2. McClanahan, S. F.; Kincaid, J. R. ${ }^{3}$ MLCT Lifetimes of Tris(2-2'-bipyridine) Ruthenium (II). Position-Dependent Deuterium Effect. J. Am. Chem. Soc. 1986, 108, 3840-3841.

3. Punzi, A.; Martin-Gassin, G.; Grilj, J.; Vauthey, E. Effect of Salt on the Excited-State Dynamics of Malachite Green in Bulk Aqueous Solutions and at Air/Water Interfaces: a Femtosecond Transient Absorption and Surface Second Harmonic Generation Study. J. Phys. Chem. C 2009, 113, 11822-11829.

4. Liang, L. H.; Shen, C. M.; Chen, X. P.; Lui, W. M.; Gao, H. J. The Size-Dependent Phonon Frequency of Semiconductor Nanocrystals. J Phys: Condens Matter 2004, 16, 267-272.

5. Jiang, Q.; Liang, L. -H.; Zhao, D. -S. Lattice Contraction and Surface Stress of fcc Nanocrystals. J. Phys. Chem. B 2001, 105, 6275-6277.

6. Jiang, Q.; Shi, H. -X.; Zhao, M. Free Energy of Crystal-Liquid Interface. Acta Mater. 1999, 47, 2109-2112. 